\title{
Therapist-supported online remote behavioural intervention for tics (ORBIT) in children and adolescents: A single-blind randomised controlled trial
}

Authorship line:

Chris Hollis $(F R C P s y c h)^{1,2,3,9}$, Charlotte L Hall $(P h D)^{1,3}$, Rebecca Jones $(M S c)^{4}$, Louise Marston $(P h D)^{5}$, Marie Le Novere $(M S c)^{5}$, Rachael Hunter $(\mathrm{MSc})^{5}$, Beverley J Brown $(P h D)^{1}$, Charlotte Sanderson $(D C l i n P s y)^{6,7}$, Per Andrén $(M S c)^{8}$, Sophie D Bennett $(P h D)^{6,7}$, Liam R Chamberlain $(B S c)^{1}$, E Bethan Davies $(P h D)^{1,3}$, Amber Evans $(M S c)^{6,7}$, Natalia Kouzoupi $(M S c)^{6,7}$, Caitlin McKenzie $(M S c)^{1}$, Isobel Heyman $(P h D)^{6,7}$, Kareem Khan $(M S c)^{1}$, Joseph Kilgariff $(B A)^{9}$, Christine Glazebrook $(P h D)^{1,3}$, David Mataix-Cols $(P h D)^{8}$, Tara Murphy $(D C l i n P s y){ }^{6,7}$, Eva Serlachius $(P h D)^{8}$, Elizabeth Murray $(P h D)^{5}$

\section{Affiliations:}

${ }^{1}$ NIHR MindTech MedTech Co-operative, Institute of Mental Health, School of Medicine, University of Nottingham, Innovation Park, Triumph Road, Nottingham, UK

${ }^{2}$ NIHR Nottingham Biomedical Research Centre, Institute of Mental Health, University of Nottingham, Innovation Park, Triumph Road, Nottingham, UK

${ }^{3}$ Division of Psychiatry and Applied Psychology, School of Medicine, University of Nottingham, Queen's Medical Centre, Nottingham, UK

${ }^{4}$ Division of Psychiatry and Priment CTU, University College London, 6th Floor Maple House, 149 Tottenham Court Road, London, UK

${ }^{5}$ Research Department of Primary Care and Population Health and Priment CTU, University College London, Upper $3^{\text {rd }}$ Floor, Royal Free Campus, Rowland Hill Street London, UK

${ }^{6}$ UCL Great Ormond Street Institute of Child Health (ICH), 30 Guilford Street, London WC1N 1EH, UK/Great Ormond Street Hospital for Children NHS Trust, Great Ormond Street, London, UK.

${ }^{7}$ Psychological and Mental Health Services, Great Ormond Street Hospital for Children NHS Foundation Trust, Great Ormond Street, London, UK

${ }^{8}$ Centre for Psychiatry Research, Department of Clinical Neuroscience, Karolinska Institutet, and Stockholm Health Care Services, Region Stockholm, Stockholm, Sweden

${ }^{9}$ Department of Child and Adolescent Psychiatry, Nottinghamshire Healthcare NHS Foundation Trust, South Block Level E, Queen's Medical Centre, Nottingham

Corresponding author:

Professor Chris Hollis

Chris.hollis@nottingham.ac.uk 
Institute of Mental Health, Division of Psychiatry and Applied Psychology, University of Nottingham, Innovation Park, Triumph Road, Nottingham, NG7 2TU, UK

\section{SUMMARY (300 word limit)}

Background: Behaviour therapy is an effective treatment in children and adolescents with tic disorders but is rarely available. Online delivery could widen access to therapy. We evaluated the efficacy of internet-delivered, therapist-supported and parent-assisted Exposure and Response Prevention (ERP) for tics.

Methods: Multi-centre, parallel group, single-blind, randomised controlled trial. Eligible participants were aged 9-17 years with Tourette syndrome/chronic tic disorder, who had not received behaviour therapy for tics within 12 months, and had a Yale Global Tic Severity Scale (YGTSS) Total Tic Severity Score (TTSS) of $>15$, or $>10$ if motor or vocal tics only. Participants were recruited via 16 patient identification centres, two study sites, or online self-referral, and were randomised (1:1) by blinded outcome-assessors to receive either 10 weeks of ERP or psychoeducation (active control). The primary outcome was YGTSS-TTSS at 3 months' post-randomisation, analysis was by intention-to-treat. The mean cost per patient for the intervention and health care costs were calculated. Registrations are ISRCTN (ISRCTN70758207) and ClinicalTrials.gov (NCT03483493).

Findings: Between $8^{\text {th }}$ May 2018 and 30 ${ }^{\text {th }}$ September 2019, 224 participants were enrolled; 112 to ERP and 112 to psychoeducation. The ERP intervention reduced YGTSS-TTSS by 2.29 points ( $95 \%$ CI: -3.86 to -0.71$)$ compared to the psychoeducation group at 3 months, an effect that increased by 6 months post-randomisation $(-2 \cdot 64,95 \%$ CI: $-4 \cdot 56$ to -0.73$)$. The average therapist time spent supporting the intervention was 2.5 hours. The additional cost per participant of the ERP intervention compared to psychoeducation was $£ 159$ (95\% CI - $£ 53$ 
to $£ 370$ ). There were two unrelated serious adverse events, both in the psychoeducation group.

Interpretation: Online-delivered, therapist-supported ERP therapy is clinically effective at reducing tics, with minimal therapist contact time. Online delivery could improve access to evidence-based treatment for tics in children and adolescents.

Funding: National Institute for Health Research, Health and Technology Assessment (HTA).

\section{INTRODUCTION}

Tic disorders such as Tourette syndrome (TS) or chronic tic disorder (CTD) are common conditions affecting up to $1 \%$ of young people. ${ }^{1}$ Tics can lead to significant impairment and isolation ${ }^{2}$ and often co-occur with other conditions. Although there are effective pharmacological treatments for tics, they are associated with side-effects such as weight-gain and cognitive dulling. ${ }^{2,3}$ Behavioural therapy (BT) demonstrates similar efficacy to pharmacotherapy for tics, ${ }^{1,3}$ with minimal adverse effects, and is recommended as first-line therapy. ${ }^{3}$

Effective behavioural therapies for tics include: Habit Reversal Training (HRT), where patients learn to detect tics and use a competing response (an incompatible action) to control them; Comprehensive Behavioural Intervention for Tics (CBIT) which combines HRT with relaxation, functional analysis and social support and Exposure and Response Prevention (ERP), where patients learn to tolerate the premonitory urge to tic and resist expressing it. In a head-to-head comparison, no difference was found in efficacy between ERP and HRT in reducing tic symptoms. ${ }^{4}$ A pivotal study demonstrated superior tic reduction and clinical improvement for children who received eight sessions of CBIT compared to supportive therapy with tic psychoeducation. ${ }^{5}$ 
However, behavioural therapy for tics is rarely available. In the United Kingdom (UK), only one in five children and adolescents with tic disorders has access, with less than half of them receiving the recommended number of sessions. ${ }^{6}$ Barriers include a shortage of trained therapists, and therapy only being offered at specialist treatment centres meaning patients often have to travel long distances. The COVID-19 pandemic has further highlighted the urgent need to offer cost-effective interventions that can be delivered remotely in digital formats. ${ }^{7}$

Across different mental health conditions, meta-analyses demonstrate that online internetdelivered cognitive behavioural therapy (iCBT) is as efficacious as face-to-face delivery and can result in substantial cost-savings. ${ }^{8}$ Evidence from studies of internet-delivered, cognitive behavioural therapy (iCBT) with adults suggests that therapist-guided interventions lead to better outcomes ${ }^{9}$ than standalone iCBT. Given the lack of specialist child therapists in this area, a blended approach whereby the core therapeutic content is delivered online in a standardised chapter format, but is supported asynchronously by a non-specialist therapist, whose primary role is to promote engagement may offer a more pragmatic solution. A metaanalysis of CBT for anxiety and depression in children argued that parents are also a potentially valuable but under researched resource to support the delivery of iCBT in children. ${ }^{10}$

Recent research in Sweden has developed an online platform to deliver therapist-supported iCBT called "BIP” (Barninternetprojektet [Child Internet Project]; http://www.bup.se/bip). The platform has been used to deliver therapy to children with a range of mental health conditions, including anxiety, and obsessive-compulsive disorder. ${ }^{11,12}$ Compared to other conditions, internet delivery of therapy for tics has received less interest. ${ }^{13}$ One small pilot study using the BIP platform compared 10 weeks of therapist-guided, parent-supported HRT against ERP in children and adolescents with tics who were followed-up at 3 and 12 months 
post-treatment. The findings indicted that the method of delivery was highly acceptable to families. Whilst both therapeutic groups demonstrated a reduction in tic severity and impairment and improved quality of life, only the group who received ERP experienced a significant reduction in tic severity. ${ }^{14}$ Although this pilot study was not designed or powered to evaluate efficacy, the results support the feasibility and promise of online ERP for treating tics and justify further investigation to assess clinical efficacy and cost-effectiveness. In the present study, we aimed to evaluate the clinical efficacy and costs of a therapist-supported, parent-assisted internet-delivered ERP programme for tics in children and adolescents in the UK.

\section{METHODS}

\section{Study design}

The Online Remote Behavioural Intervention for Tics (ORBIT) trial was a two-arm, superiority parallel group, single-blind, multi-centre randomised control trial (RCT). It commenced in October 2018 with an anticipated completion date of September 2021. The trial was conducted across two Child and Adolescent Mental Health Services (CAMHS) in England. Site one (Queen's Medical Centre, Nottingham) was based in a mid-sized city and was a regional centre for tic treatment. Site two (Great Ormond Street Hospital, London) was a large metropolitan national paediatric centre of excellence.

The trial had two phases: Phase 1, a per-protocol follow-up for 6 months post-randomisation and Phase 2, a naturalistic follow-up for 18 months post-randomisation. The findings from Phase 1 are presented here.

Ethical and Health Research Authority (HRA) approval was received from North West Greater Manchester Research Ethics Committee on 23 March 2018 (ref.:18/NW/0079). The 
published trial protocol is available online ${ }^{15}$ and was approved by an independent trial steering committee (TSC) and data monitoring committee (DMC). Two substantial amendments were made and can be found in the appendix $\mathrm{p} 1$. The trial was prospectively registered with the ISRCTN (ISRCTN70758207) and ClinicalTrials.gov (NCT03483493).

\section{Participants}

Eligible participants were aged 9-17 years with a moderate/severe tic disorder (TS or CTD) defined as scores on the Yale Global Tic Severity Scale (YGTSS) ${ }^{16}$ Total Tic Severity Score (TTSS) of $>15$, or $>10$ if only motor or vocal tics were present in the last 7 days. All participants were required to have broadband and smart phone/regular desktop/laptop computer access and the capacity to provide informed, written consent. Participants aged under 16 years were required to have a parent/guardian consent.

Exclusion criterion were: engaged in structured behavioural intervention for tics (e.g., HRT/CBIT or ERP) within the preceding 12 months or about to start; changed (i.e. starting or stopping) medication for tics within the previous two months; alcohol/substance dependence, psychosis; suicidality or anorexia nervosa (assessed via the Development and Well Being Assessment - DAWBA), ${ }^{17}$ suspected moderate/severe intellectual disability (assessed via Child and Adolescent Intellectual Disability Screening (CAIDS-Q); ${ }^{18}$ immediate risk to self or others; parent/carer of child unable to speak or read/write English.

Participants were recruited either by referral from one of 16 participating CAMHS or community paediatric clinics in England and the two study sites or by self-referral via Tourettes Action (UK tic disorder charity) website or the study website. Researchers (outcome assessors) completed an initial telephone consultation to determine likely eligibility and parents/carers completed the online DAWBA. Potential participants deemed eligible after 
this initial screen attended a baseline assessment at one of the two study sites where assessors conducted further eligibility assessments including the YGTSS and CAIDS-Q. Written informed consent was obtained from participants or their parents/carers prior to undertaking the baseline assessment.

\section{Randomisation and masking}

Participants were randomly allocated in a 1:1 ratio to receive either 10 weeks of online, remotely delivered, therapist-supported ERP for tics or therapist-supported education about tics, referred to as psychoeducation (the active control). Outcome assessors randomly assigned participants using a secure web-based randomisation system developed by Sealed Envelope (https://www.sealedenvelope.com/) and managed by Priment Clinical Trials Unit, following specified standard operating procedures. Randomisations were stratified by study site using block randomisation with varying block sizes. Therapists and an independent assessor who did not conduct outcome assessments were informed of the allocation via email. The independent assessor verified that each participant was assigned to their allocated intervention - no instances of incorrect allocation were observed. Outcome assessors, statisticians, health economists, the trial manager and chief investigator were blind to group allocation. Participants were not directly informed of their allocation but may have been able to determine allocation once treatment commenced. Participants were reminded about the importance of masking at each follow-up, however, four instances of breaks of allocation concealment were reported to the trial manager. In all instances the child disclosed information about their treatment to the outcome assessor at the end of the follow-up assessment. In these cases, subsequent follow-ups were conducted by an alternative, blinded assessor. All instances were reviewed by the independent TSC and DMC for monitoring. 


\section{Procedures}

The treatments were delivered via the secure online Swedish "BIP" platform. Participants and their parent/carers created their log-in details at the baseline assessment and set a treatment start date within 1-week of randomisation. Where possible, participants were briefly introduced to their therapist in person at the baseline assessment. The therapists assigned the participant to their allocated treatment and emailed a reminder to log in on their start date. The treatment content has been described elsewhere, ${ }^{15}$ In summary, information was presented in chapters, which the family (child/adolescent and parent/carer) were requested to work-through. The therapist aimed to have 10-20 minutes contact time with the participants (combined contact time with the parent/carer and/or child/adolescent) each week to check progress, encourage motivation and answer questions, but did not deliver therapeutic content. Both the ERP intervention and the psychoeducation consisted of 10 chapters for the child/adolescent and 10 different chapters for parent/carers, designed to be delivered over 10 weeks. The therapist provided support for either ERP or psychoeducation through asynchronous contact (typically delivered via online messages sent through BIP) during these 10 weeks.

The internet-delivered ERP intervention was adapted from previously published treatment manuals by Verdellen et al. ${ }^{19}$ Participants were requested to first practice controlling all of their tics for increasingly long periods of time (response prevention), and then to deliberately provoke the premonitory urges whilst not releasing any tics (exposure and response prevention). Specific triggers to provoke the urge to tic were identified and used by participants, and then employed in everyday situations to improve generalizability of the gains. The psychoeducation comparator focussed on the history, prevalence and risk typically associated with tic disorders, and advised healthy habits, with no information on tic control. For both interventions, the main treatment information was delivered via ten child-completed 
chapters; participants were considered "treatment completers" if child chapters 1-4 were completed. The 10 parent chapters focused on how best to support the child during their treatment.

Therapists (graduate level education) were not required to have previous experience in treating tic disorders but were trained on the platform and its contents and received regular expert supervision. Further details can be found elsewhere. ${ }^{20}$

Participants completed brief online measures mid-point through treatment ( 3 and 5 weeks) and completed online and outcome-assessor rated measures at baseline, 3, 6, 12 and 18 months post-randomisation. All follow-up outcome-assessor rated measures were completed remotely (via videoconferencing or telephone). Only the baseline appointment was conducted in person at one of the two study sites.

\section{Outcomes}

The primary outcome was tic severity at 3 months post-randomisation as measured by the YGTSS-TTSS. This is a semi-structured interview that combines separate scales of motor tics (score 0-25) and vocal tics (score 0-25), providing a total score 0-50, with higher scores indicating greater severity. It was completed by a blinded outcome-assessor. All outcomeassessors completed mandatory structured training on the YGTSS prior to starting and agreement with an expert rater was assessed every 6 months; full details can be found in appendix $\mathrm{p} 2$.

Secondary outcomes were obtained at baseline, 3 and 6 months post-randomisation, through interviews conducted by the blinded outcome assessors with the parent/carer and child/young person. They comprised: reduction in tic related impairment assessed through the YGTSS impairment scale (score 0-50); a global assessment of symptom improvement measured via the Clinical Global Impressions - Improvement scale (CGI-I) ${ }^{21}$ and global functioning 
assessed via the Children's Global Assessment Scale (CGAS) 22 ; service use using a modified version of the Child and Adolescent Service Use Schedule (CA-SUS) to include specific specialist tic disorder services and medications. ${ }^{23}$

Parent/carers completed secondary outcomes online including measures of general behavioural and emotional difficulties (Strengths and Difficulties Questionnaire; SDQ); ${ }^{24}$ generic health-related quality of life (proxy-rated child-health-utility-9D; CHU9D); ${ }^{25}$ adverse events or side-effects (modified version of the Hill and Taylor ${ }^{26}$ side-effects scale). A parent assessment of tics measured via the Parent Tic Questionnaire (PTQ ${ }^{27}$ was completed at these times and also at 5 weeks (mid-treatment).

Additional outcomes completed online by the child/adolescent included: generic quality of life (CHU9D) and a disease-specific measure of quality of life (Child and Adolescent Gilles de la Tourette Syndrome Quality of Life Scale; C\&A-GTS-QOL). ${ }^{28}$ Two additional measures were completed by the child/adolescent at 5 weeks (mid-treatment) as well as at baseline, 3 and 6 months, namely the Mood and Feelings Questionnaire (MFQ) ${ }^{29}$ and the Spence Childhood Anxiety Scale (SCAS) ${ }^{30}$. For the purpose of this study, a measure of treatment credibility was developed and completed online by parent/carers and child/adolescent at 3 weeks. ${ }^{15}$

Adverse events and side-effects were formally sought and recorded at each follow-up through the side-effects scale and MFQ. Participants were also encouraged to report them to their therapist or outcome assessor (see appendix p4-6).

\section{Statistical analysis}

Based on findings of other trials, the sample size was calculated in order detect a clinically important average difference of 0.5 of a standard deviation between ERP and 
psychoeducation with $90 \%$ power at $\mathrm{p}<0.05$ (two-sided). When allowing for $20 \%$ dropout, this required a total sample size of 220 participants.

Statistical analyses were conducted using Stata (version 16) in line with a predefined statistical analysis plan (SAP) approved by the TSC. Analysis was performed on an intentionto-treat basis, in which participants were analysed according to their allocated group. In line with the SAP, confidence intervals are reported rather than p-values.

Baseline demographic characteristics of participants, as well as their clinical and mental health outcomes at baseline and 3 and 6 months follow up, were summarised by randomised group using mean (standard deviation [SD]) or count (percentage) respectively for continuous and categorical data. The primary outcome was estimated using a linear regression model with YGTSS-TTSS at 3 months as the outcome and study group as the main explanatory variable, adjusting for YGTSS-TTSS at baseline and site (Nottingham/London). Similar linear regression models were fitted to estimate the effect of the intervention on secondary outcomes at mid-treatment, 3 months and 6 months follow up (postrandomisation). The statistical model for the CGI-I did not adjust for baseline since this is a measure of change. Two unplanned subgroup analyses explored whether the effect of the intervention on the primary outcome was modified by either anxiety diagnosis or attention deficit hyperactivity disorder (ADHD) diagnosis. The statistical models were the same as for the main analysis of the primary outcome, with the addition of a fixed effect of the comorbidity (anxiety or ADHD) and an interaction between the comorbidity and study arm. A separate full economic evaluation will be conducted at the end of the 18-month follow-up (Phase 2) as the follow-up duration of 6-months is insufficient for calculating an incremental cost per quality-adjusted life year (QALY) gained. Here we explore the cost of delivering the ERP and psychoeducation interventions, examine relevant healthcare resource use, and 
evaluate the suitability of the CHU9D for calculating QALYs in an 18-month analysis. Further details on the method and findings can be found in the appendix (p7-23).

\section{Role of the funding source}

The study was publicly funded by the UK National Institute for Health Research (NIHR) Health Technology Assessment (Ref: 16/17/02). The funders had no role in the study design, data collection, data analysis, data interpretation, writing of the report, or the decision to submit the paper for publication. The corresponding author had full access to all the data and had final responsibility for the decision to submit for publication.

\section{RESULTS}

Participant enrolment began on $8^{\text {th }}$ May 2018 and ended $30^{\text {th }}$ September 2019. The last participant completed the 6-month follow-up on $30^{\text {th }}$ April 2020; at this point Phase 1 of the ORBIT trial was completed. Of the 445 potential participants who registered their interest in the trial, 210 were excluded following an initial telephone screen and/or DAWBA results, thus 235/445 (52.8\%) attended a baseline assessment and were consented into the trial. Eleven were found ineligible after the further screening measures; thus 224/445 (50.3\%) potential participants were randomised, of whom 112/224 were assigned to the ERP intervention and 112/224 were assigned to the psychoeducation group. Figure 1 shows the flow of participants through the trial.

$$
<<\text { Insert Figure 1 }>>
$$

Participants had a mean age of 12 years, were predominately male (79\%) and defined their ethnicity as white (87\%). Only $13 \%$ of participants were receiving medication for tics (Table 
1). Baseline scores on the primary and secondary outcome measures were similar across the trial arms (Table 2).

$$
\begin{aligned}
& <<\text { Insert Table } 1>> \\
& <<\text { Insert Table } 2>>
\end{aligned}
$$

Primary outcome data were collected from 99/112 (88.4\%) in the intervention group and $105 / 112(93.7 \%)$ in the psychoeducation group. The only predictor of missingness was site, which was included as a covariate in the statistical model.

Mean YGTSS-TTSS at 3 months in the ERP group was 23.9 (SD: 8.2) compared to 26.8 (SD: 7.3) in the psychoeducation group. The mean total decrease YGTSS-TTSS at 3-months was $4.5(16 \%)$ for ERP vs $1.6(6 \%)$ for psychoeducation, and at 6 months was $6.9(24 \%)$ for ERP vs $3.4(12 \%)$ for psychoeducation. The adjusted (for baseline and site) analysis of the primary outcome at 3 months revealed that the ERP intervention reduces YGTSS-TTSS by $2 \cdot 29$ points (95\% CI: -3.86 to $-0.71 ; p=0.005)$ in comparison to the psychoeducation with an effect size (ES) of $-0.31(95 \%$ CI -0.52 to -0.10$)$ (Table 3; Figure 2).

$$
\begin{aligned}
& <<\text { Insert Table } 3>> \\
& <<\text { Insert Figure 2>> }
\end{aligned}
$$

This adjusted effect on tics (YGTSS-TTSS) was slightly increased at 6 months (estimated difference: $-2 \cdot 64 ; 95 \%$ CI: -4.56 to -0.73$)$ with an ES of $-0.36(95 \% \mathrm{CI}-0.62$ to -0.10$)$. Figure 3 presents a forest plot of standardised effect sizes for primary and secondary outcomes.

The secondary outcome of parent reported tic (PTQ) symptoms supported the primary outcome finding at 3 months $(-9 \cdot 44 ; 95 \% \mathrm{CI}:-15 \cdot 37$ to $-3 \cdot 51)$ and 6 months $(-8 \cdot 60 ; 95 \% \mathrm{CI}$ : 14.43 to $-2 \cdot 77)$. There was no statistically significant difference in tic related impairment as measured by the YGTSS impairment scale at either time point (Table 3). Further, unplanned 
analysis of the YGTSS-TTSS separately for motor and vocal tics replicated the pattern of the primary outcome showing greater improvement in the ERP group at 3 months $(-1 \cdot 28 ; 95 \%$ CI: $-2 \cdot 07$ to $-0 \cdot 49)$ and 6 months $(-1 \cdot 19 ; 95 \%$ CI: $-2 \cdot 20$ to $0 \cdot 17)$ for motor tics. For vocal tics, this only reached statistical significance at 6 months (-1.56; 95\% CI: $-2 \cdot 28$ to $-0 \cdot 29)$.

Other secondary outcomes including parent-reported general emotional and behavioural functioning (SDQ), young person reported low mood (MFQ) and outcome assessor reported overall functioning (CGAS) were not significantly different between the two groups at 3 or 6 months. Although there was no difference in young person reported anxiety (SCAS) at 3 months, there was a difference in favour of the ERP group at 6 months $(-5 \cdot 10 ; 95 \%$ CI: $-9 \cdot 70$ to -0-50). Conversely, the young person reported tic-specific quality of life (C\&A-GTS-QOL) and the outcome-assessor completed perception of global improvement (CGI-I) showed superior results in the ERP group than psychoeducation at 3 months (CGI $-0 \cdot 41$; $95 \%$ CI: $0 \cdot 71$ to $-0 \cdot 11$. C\&A GTS-QOL $-4 \cdot 81 ; 95 \%$ CI: $-8 \cdot 79$ to $-0 \cdot 83$ ) but no difference at 6 months.

\section{$<<$ Insert Figure 3>>}

There was no difference in scores on the MFQ or PTQ at the mid-point of the intervention (see appendix p.24). A further unplanned analysis revealed no evidence to suggest that the ERP therapy had a different effect either in participants with or without a comorbid anxiety disorder or with or without comorbid ADHD (see appendix p24). An additional unplanned analysis (see Table 4) comparing positive treatment response as defined by a rating of 1 or 2 (very much/much improved) on the CGI-I, showed a significantly greater treatment response with ERP at 3 months $(36 \%$ [95\% CI 26-45], $n=101)$ than for psychoeducation $(20 \%$ [95\% CI $12-28], n=100)$, OR $2 \cdot 22$ (95\% CI: $1 \cdot 17$ to $4 \cdot 20)$. This superior treatment response was sustained at 6 months for ERP (47\% [95\% CI 37- 57], $n=93)$ compared to psychoeducation 
(29\% [95\% CI 20-39], n=93), OR $2 \cdot 20$ (95\% CI: $1 \cdot 20$ to 4.04). Table 4 shows there was a higher number of responders at both time points in the ERP group.

$<<$ Insert Table 4>>

Two serious adverse events (SAE) were recorded during the trial, affecting two participants who were both in the psychoeducation group. Both SAEs were reviewed by the independent TSC and DMC and deemed unrelated to trial participation. There were slightly fewer AEs in the ERP group compared to psychoeducation (359 vs 433) and fewer participants in the ERP group experienced one or more adverse events $(n=88 / 112 ; 79 \%)$ than in the psychoeducation group ( $\mathrm{n}=94 / 112 ; 84 \%)$; see appendix p6 for further details.

Overall, engagement with the intervention was high in both groups, with minimum treatment completion ( $\geq 4$ chapters) rates of $88 \%(99 / 112)$ in the ERP group and $94 \%(105 / 112)$ in the psychoeducation group. Similarly, number of log-ins were comparable across both groups, although Table 5 shows slightly higher number of log-ins for the participants in the ERP group. Perception of treatment suitability and credibility were also high across both groups (see Table 5). Approximately 15 minutes more therapist time was spent supporting the participants in the ERP group compared to the psychoeducation, however, therapist time required to effectively support the intervention was low at approximately 2.5 hours contact time per participant, approximately 15 minutes per week (combined child/young person and parent/carer contact time).

$<<$ Insert Table 5>>

The fixed yearly cost of delivering the intervention was $£ 103.64$ per participant (calculated on $£ 8494$ yearly cost of the BIP platform and total cost of supervision and training at 
$£ 14719 \cdot 78)$. As both interventions were delivered on the same platform there was no difference in fixed costs.

A variable cost was also calculated at $£ 0.17$ for each time a participant or one of their parents logged in to account for the SMS notification. Table 6 shows there was a small but significant difference between the two groups in the variable costs of the platform resulting from more platform logins and slightly more therapist contact time in the ERP intervention group (see appendix p 12-14 and table 6). There were no significant differences in wider health care costs (see appendix). Combining fixed and variable costs and including wider health care costs delivering the ERP intervention cost $£ 159$ (95\% CI -£-£53 to $£ 370)$, per participant compared to the psychoeducation group.

$<<$ Insert Table 6>>

\section{DISCUSSION}

To our knowledge, ORBIT is the first adequately-powered, randomised, controlled trial of an online internet-delivered behavioural intervention for tics in children and adolescents, and the largest trial of any behavioural treatment for tics. The results support the clinical efficacy of online delivery of therapist-supported behavioural intervention for tics. The trial recruited ahead of time and target, reflecting a significant unmet treatment need in the population. Retention to the primary outcome at the primary endpoint (90\%) and 6-month follow-up $(>80 \%)$ were excellent. Acceptability and safety of the intervention was high. Analysis of our primary outcome (tic severity at 3 months post-randomisation) indicated a significant effect in favour of therapist-supported ERP compared to supported psychoeducation. Importantly, the therapeutic effect was durable and slightly increased at 6-months follow-up. Compared with the psychoeducation comparator, participants were twice as likely to show a positive 
treatment response with the ERP intervention with just under half (47\%) having responded positively by 6-month follow-up.

The participants in this trial had a moderate to severe level of baseline tic severity (mean YGTSS-TTSS 28.4 SD 7.7), which is approximately half a standard deviation higher than reported in previous face-to-face behavioural treatment trials. ${ }^{2,5}$ The trial design minimised the clinical comorbidity exclusions, resulting in a sample broadly representative of real-world clinical practice, and included participants with autism spectrum disorder (ASD), a group usually excluded in similar behavioural intervention trials. In the behavioural intervention group, just under one third had a co-existing anxiety disorder and just under one quarter had ADHD. The reduction in tics associated with the behavioural intervention was similar in those with and without co-existing anxiety and ADHD diagnoses. A relatively small proportion of participants (13\%) were concurrently receiving tic medication. A further strength of the design was the inclusion of an active comparator arm controlling for nonspecific effects of therapist contact, homework assignments, and online access. The uptake of both the ERP and psychoeducation was excellent.

In our previous systematic review, ${ }^{2}$ we identified two superiority trials of face-to-face behavioural therapy (HRT/CBIT) for tics $(\mathrm{N}=133)$ with evidence of a medium-sized effect in improving tics in favour of behavioural therapy (HRT/CBIT) when compared to waitlist/supportive psychotherapy (pooled effect size 0.64 ; 95\% CI 0.29-0.99). ${ }^{2,4}$ The magnitude of effect of this online ERP is about half the size reported from previous superiority trials of face-to-face behaviour therapy for tics. ${ }^{2}$ However, it is difficult to make direct comparisons of therapeutic efficacy with previous trials of face-to-face behavioural therapy given that this trial had a higher level of baseline tic severity, fewer co-morbidity exclusions, a lower proportion of participants receiving tic medication, longer follow-up and a potent active comparator. In practice, the direct comparison of efficacy may also be 
misleading with respect to implementation because the purpose is not to replace face-to-face therapy, but to allow this scare resource to be better targeted to those who need it most and to offer an effective online intervention to a much larger population of children/adolescents who are currently unable to access any behavioural treatment for tics.

A major difference between online delivery and face-to-face behavioural therapy for tics is the reduced amount of therapist time, required skill level of the therapist and cost. The total therapist contact time in the current trial was around 2.5 hours compared to 9-10 hours in comparable evidence-based face-to-face behavioural therapy for tics. Given the shortage of highly trained therapists with expertise in tic disorders and limited access to behavioural therapy, online delivery of behavioural therapy for tics has the potential to greatly expand the reach of effective behavioural interventions. From a public health perspective, with more efficient use of therapist time it should be possible to treat four people for every one person treated with face-to-face therapy. In addition, the requirement for less experienced therapists to support online behavioural therapy should expand the potential pool of therapists and thereby further extend the availability of online delivered behavioural therapy for tics. A further strength of the online delivery model is that fidelity of therapeutic content is built into the intervention, making transfer to real-world effectiveness much less susceptible than in traditional face-to-face therapy to therapeutic drift and the skill level of individual therapists.

Although a full economic evaluation of the intervention was conducted, the limited follow-up duration of 6-months meant that a meaningful incremental cost per QALY analysis in line with guidance could not be conducted as it would not capture the full benefits of the intervention. A further naturalistic follow-up of this trial to 18-months (Phase 2) is being conducted which will be used to calculate cost and QALYs over a longer time horizon. Further implementation research will also be required to determine how best to integrate online behavioural therapy for tics within treatment pathways. For example, digital/online 
delivery may work best as a first-line behavioural intervention with non- or poor responders being 'stepped-up' to more intensive face-to-face therapy. A further model to evaluate would be the 'blending' of online and face-to-face therapy for more complex cases, thereby reducing the overall number of face-to-face sessions required.

While an economic evaluation including QALYs is required to provide comparable evidence of cost-effectiveness, evidence from this trial suggests that implementation of online therapist-supported behavioural therapy has a high probability of cost-effectiveness for reduction in tic symptoms, with a non-significant increase in costs, and the potential to greatly increase the availability of effective behavioural treatment for children and adolescents with tic disorders.

\section{RESEARCH IN CONTEXT PANEL}

\section{Evidence before this study:}

In 2016 we conducted a systematic review of interventions for children and adolescents with tic disorders. Twenty-one databases covering medical/health (e.g. Medline, CENTRAL, PsycINFO), education (e.g. ERIC), social care (e.g. Social Services Abstracts) and grey literature (e.g. Health Management Information Consortium) topics were searched for studies in any language. Searches were conducted from database inception to 1st January 2013 and updated in October 2014. The search strategy included key words (tic or tics or tourette\$) and relevant subject headings. This search identified two randomised controlled trials (RCTs) of habit reversal training $(\mathrm{HRT}) /$ comprehensive behavioural intervention $(\mathrm{CBIT})(\mathrm{SMD}=0.64$; 
95\% CI 0.99-0.29; $\mathrm{N}=133$ ). In 2020, we updated this search and found no new trials of behavioural interventions for tics in children and adolescents. In 2017, we conducted a metareview of scoping, narrative, systematic or meta-analytical reviews investigating the effectiveness of digital health interventions (DHIs) for mental health problems in children and adolescents. We also updated a systematic review of randomised controlled trials (RCTs) of DHIs for CYP published in the previous 3 years. The search was run on 11 online databases (Allied and Complementary Medicine, Ovid, MEDLINE, PsychINFO, PsychARTICLES, Embase, PubMed, ASSIA, Cochrane Library, CINAHL and Web of Science), and a limited keyword search was also performed on the JMIR Publications database. The search identified 30 unique RCTs of digital health interventions, with no digital intervention studies identified that focussed on treatment of tic disorders.

We have previously reported that only one in five children and adolescents in the UK have access to structured behavioural interventions for tics, and of these, less than half receive a minimum effective dose of therapy. Widely accessible and effective online behavioural interventions for tics are urgently needed.

\section{Added value of this study:}

This is the first RCT, to our knowledge, that reports the clinical efficacy, safety and costs of an adequately powered therapist and parent-supported online behavioural intervention for tics in children aged 9 to 17 years. We demonstrated that this 10 -week online intervention was highly acceptable, well tolerated, and effective in reducing tics. The magnitude of the effect on tic reduction was durable with a slightly greater effect 3 months after treatment ended (6month follow-up). Approximately a quarter of the therapist contact time is required compared to face-to-face behaviour therapy.

\section{Implications of all the available evidence:}


Data from this trial supports the implementation of online delivered behavioural therapy for tics as an efficient approach to increase the population reach of an effective treatment for children and adolescents with tic disorders. Further research is needed to determine the optimum care pathways with respect to sequencing and integration of digital and face-to-face behavioural therapy for tics in children and adolescents.

\section{Contributors}

$\mathrm{CH}$ was the chief investigator and conceived the study. The study design was conceived and written by CH, CLH, PA, TM, DM-C, EM, LM, IS, ES, RJ, RH, and CG. CLH wrote the trial protocol with input from all co-authors. $\mathrm{CH}, \mathrm{CLH}, \mathrm{EM}, \mathrm{SB}, \mathrm{TM}, \mathrm{CS}, \mathrm{BJB}$ were responsible for study implementation and general project management. BJB, CS, KK, CM were responsible for recruitment and follow-ups. TM and JK provided therapist supervision. LRC, EBD, AE, NK were the trial therapists. CLH oversaw trial management. LM and RJ designed and wrote the statistical analysis plan. RJ and LM conducted the analysis. RH designed the economic evaluation; RH and MLN wrote the health economic analysis plan. MLN and RH conducted the economic evaluation. $\mathrm{CLH}$ and $\mathrm{CH}$ drafted the original manuscript. All authors contributed to the interpretation of the data and re-drafts. All authors had full access to the study data and take responsibility for the integrity and accuracy of the data. $\mathrm{CH}$ is guarantor.

\section{Declaration of interests}

All authors have completed the ICMJE uniform disclosure from. Aside from receiving funding from NIHR to support their salaries CLH, LM, EBD, RJ, KK, BJB, CS, CM, ES, PA, TM, IS, JK, RH, MLN, AE, LRC, NK, SB, CG, EM declare no conflict of interests. CH declares he was Principal Investigator on a grant from the National Institute of Health Research (NIHR) Health Technology Assessment programme to conduct an Evidence 
Synthesis on the treatments for tics and Tourette syndrome in children and young people' HTA Project:10/142/01. DM-C reports personal fees from Elsevier, personal fees from UpToDate Inc. outside the submitted work.

\section{Funding}

This research was funded by the NIHR Heath Technology Assessment (HTA) (Ref 16/19/02). The views expressed are those of the author(s) and not necessarily those of the NHS, the NIHR or the Department of Health. CH, CLH, EBD, CG and acknowledge the financial support of the NIHR Nottingham Biomedical Research Centre and NIHR MindTech MedTech Co-operative. The study sponsor and funders have no role in study design, including; collection, management, analysis and interpretation of data; writing of the report; and the decision to submit the report for publication. The corresponding author $(\mathrm{CH})$ had full access to all the data in the study and had final responsibility for the decision to submit for publication.

\section{Acknowledgements}

We would like to thank additional members who supported the ORBIT team; Anne Marie Downey, Natalia Lago, Jennifer L Martin, Roz Shafran, Sue Brown and Michael Craven. We would like to thank Tourettes Action for their support with the trial. We particularly acknowledge Dr Seonaid Anderson for her ongoing help and advice. We would like to thank our Patient and Public Involvement (PPI) members for their help, including: Debbie Butler, Julie Bryant, James Bungay, Claire Bungay, Sandra Wang, Marco Wang, Alison Neave, Matthew Neave, Rachel Jopling, and Luke Jopling. We thank members of our Trial Steering Committee: Prof Edmund Sonuga-Barke (Chair), Mrs Neelam Gurav, Dr Prathiba Chisabesan, Dr Kim Goldsmith, Dr David Manley, and Dr Cara Verdellen. We also thank members of our Data Monitoring Committee: Prof Stephen Scott (Chair), Dr Uttom Chowdhury, and Prof 
Richard Emsley. We would also like to thank Angela Summerfield for her continued administrative support and help.

We also acknowledge that all research at Great Ormond Street Hospital NHS Foundation Trust and UCL Great Ormond Street Institute of Child Health is made possible by the NIHR Great Ormond Street Hospital Biomedical Research Centre. This work used services from the eHealth Core Facility at Karolinska Institutet, which is supported by the Strategic Research Area Healthcare Science (SFO-V).

\section{Data sharing agreement}

Will individual participant data be available (including data dictionaries)?

Yes

What data in particular will be shared?

Individual participant data that underlie the results reported in this article, after deidentification (text, tables, figures, and appendices).

What other documents will be available?

Study protocol, statistical analysis plan, informed consent form, patient information sheets.

When will data be available (start and end dates)?

Beginning 3 months and ending 5 years following article publication.

By what mechanism will data be made available?

Proposals should be directed to priment@ucl.ac.uk to gain access, data requestors will need to sign a data access agreement.

With whom?

Researchers who provide a methodologically sound proposal 
For what types of analyses?

To achieve aims in the approved proposal. 


\section{REFERENCES}

1. Hollis C, Pennant M, Cuenca J, et al. Clinical effectiveness and patient perspectives of different treatment strategies for tics in children and adolescents with Tourette syndrome: a systematic review and qualitative analysis. Health Technol Asses 2016; 20(4): 1-450.

2. Whittington C, Pennant M, Kendall T, et al. Practitioner Review: Treatments for Tourette syndrome in children and young people-a systematic review. J Child Psychol Psyc 2016; 57(9): 988-1004.

3. Roessner V, Plessen KJ, Rothenberger A, et al. European clinical guidelines for Tourette syndrome and other tic disorders. Part II: pharmacological treatment. Eur Child Adoles Psy 2011; 20(4): 173-96.

4. Verdellen CW, Keijsers GP, Cath DC, Hoogduin CA. Exposure with response prevention versus habit reversal in Tourettes's syndrome: a controlled study. Behav Res Ther 2004; 42(5): 501-11.

5. Piacentini J, Woods DW, Scahill L, et al. Behavior therapy for children with Tourette disorder: a randomized controlled trial. JAMA 2010; 303(19): 1929-37.

6. Cuenca J, Glazebrook C, Kendall T, et al. Perceptions of treatment for tics among young people with Tourette syndrome and their parents: a mixed methods study. BMC Psychiatry 2015; 15(1): 46.

7. Torous J, Myrick KJ, Rauseo-Ricupero N, Firth J. Digital mental health and COVID19: Using technology today to accelerate the curve on access and quality tomorrow. JMIR Mental Health 2020; 7(3): e18848.

8. Andersson G, Titov N, Dear BF, Rozental A, Carlbring P. Internet-delivered psychological treatments: from innovation to implementation. World Psychiatry 2019; 18(1): $20-8$. 
9. Palmqvist B, Carlbring P, Andersson G. Internet-delivered treatments with or without therapist input: does the therapist factor have implications for efficacy and cost? Expert Rev Pharm Out 2007; 7(3): 291-7.

10. Pennant ME, Loucas CE, Whittington C, et al. Computerised therapies for anxiety and depression in children and young people: a systematic review and meta-analysis. Behaviour Research and Therapy 2015; 67: 1-18.

11. Lenhard F, Vigerland S, Andersson E, et al. Internet-delivered cognitive behavior therapy for adolescents with obsessive-compulsive disorder: an open trial. PLoS One 2014; 9(6): e100773.

12. Vigerland S, Ljótsson B, Thulin U, Öst L-G, Andersson G, Serlachius E. Internetdelivered cognitive behavioural therapy for children with anxiety disorders: A randomised controlled trial. Behav Res Ther 2016; 76: 47-56.

13. Hollis C, Falconer CJ, Martin JL, et al. Annual Research Review: Digital health interventions for children and young people with mental health problems-a systematic and meta-review. J Child Psychol Psyc 2017; 58(4): 474-503.

14. Andrén P, Aspvall K, de la Cruz LF, et al. Therapist-guided and parent-guided internet-delivered behaviour therapy for paediatric Tourette's disorder: a pilot randomised controlled trial with long-term follow-up. BMJ Open 2019; 9(2): e024685.

15. Hall C, Davies E, Andrén P, et al. Investigating a therapist-guided, parent-assisted remote digital behavioural intervention for tics in children and adolescents- 'Online Remote Behavioural Intervention for Tics'(ORBIT) trial: protocol of an internal pilot study and single-blind randomised controlled trial. BMJ Open 2019; 9(1): e027583.

16. Leckman JF, Riddle MA, Hardin MT, et al. The Yale Global Tic Severity Scale: initial testing of a clinician-rated scale of tic severity. Journal of the American Academy of Child \& Adolescent Psychiatry 1989; 28(4): 566-73. 
17. Goodman R, Ford T, Richards H, Gatward R, Meltzer H. The development and well-being assessment: Description and initial validation of an integrated assessment of child and adolescent psychopathology. Journal of Child Psychology and Psychiatry 2000; 41(5): 645-55.

18. McKenzie K, Murray GC, Murray AL. The Validity of the Child and Adolescent Intellectual Disability Screening Questionnaire (CAIDS-Q) with children aged 6-7 years, 11 months: A brief report. Psychiat Res 2013; 210(2): 675-7.

19. Verdellen C, Van De Griendt J, Kriens S, Van Oostrum I. Tics - Therapist Manual. Amsterdam: Boom Publishers; 2011.

20. Chamberlain LR, Hall CL, Andrén P, et al. Therapist-Supported Online Interventions for Children and Young People With Tic Disorders: Lessons Learned From a Randomized Controlled Trial and Considerations for Future Practice. JMIR Mental Health 2020; 7(10): e19600.

21. Guy W. ECDEU assessment manual for psychopharmacology. US Department of Health, and Welfare 1976: 534-7.

22. Shaffer D, Gould MS, Brasic J, et al. A children's global assessment scale (CGAS). Arch Gen Psychiat 1983; 40(11): 1228-31.

23. Byford S, Barrett B, Roberts C, et al. Cost-effectiveness of selective serotonin reuptake inhibitors and routine specialist care with and without cognitive-behavioural therapy in adolescents with major depression. Brit J Psychiat 2007; 191(6): 521-7.

24. Goodman R. The extended version of the Strengths and Difficulties Questionnaire as a guide to child psychiatric caseness and consequent burden. Journal of Child Psychology and Psychiatry 1999; 40(5): 791-9.

25. Stevens K. The Child Health Utility 9D (CHU9D). A new, paediatric, preferencebased measure of health related quality of life PRO Newsletter 2010; 43: 11-2. 
26. Hill P, Taylor E. An auditable protocol for treating attention deficit/hyperactivity disorder. Arch Dis Child 2001; 84(5): 404-9.

27. Chang S, Himle MB, Tucker BT, Woods DW, Piacentini J. Initial psychometric properties of a brief parent-report instrument for assessing tic severity in children with chronic tic disorders. Child Fam Behav Ther 2009; 31(3): 181-91.

28. Cavanna AE, Luoni C, Selvini C, et al. Disease-specific quality of life in young patients with Tourette syndrome. Pediatr Neurol 2013; 48(2): 111-4.

29. Angold A, Costello EJ, Messer SC, Pickles A. Development of a short questionnaire for use in epidemiological studies of depression in children and adolescents. Int J Meth Psych Res 1995.

30. Spence SH. A measure of anxiety symptoms among children. Behav Res Ther 1998; 36(5): 545-66. 
Tables

Table 1. Baseline characteristics of participants

\begin{tabular}{|c|c|c|}
\hline & $\begin{array}{c}\begin{array}{c}\text { Psychoeducation } \\
\text { (control) }\end{array} \\
\text { (N = 112) } \\
\text { N }(\%)\end{array}$ & $\begin{array}{c}\text { ERP } \\
\text { (intervention) } \\
(\mathbf{N}=\mathbf{1 1 2}) \\
\mathrm{N}(\%)\end{array}$ \\
\hline Age at randomisation (years) - Mean (SD) & $12.4(2.1)$ & $12.2(2.0)$ \\
\hline \multicolumn{3}{|l|}{ Gender } \\
\hline Male & $87(78 \%)$ & $90(80 \%)$ \\
\hline Female & $25(22 \%)$ & $22(20 \%)$ \\
\hline \multicolumn{3}{|l|}{ Ethnicity } \\
\hline White & $99(88 \%)$ & $96(86 \%)$ \\
\hline Asian & $3(3 \%)$ & $7(6 \%)$ \\
\hline Black & $0(0 \%)$ & $1(1 \%)$ \\
\hline Mixed & $7(6 \%)$ & $3(3 \%)$ \\
\hline Other & $1(1 \%)$ & $0(0 \%)$ \\
\hline Not given & $2(2 \%)$ & $5(4 \%)$ \\
\hline \multicolumn{3}{|l|}{ Main caregiver in trial } \\
\hline Mother & $101(90 \%)$ & $93(83 \%)$ \\
\hline Father & $10(9 \%)$ & $16(14 \%)$ \\
\hline Grandmother & $1(1 \%)$ & $1(1 \%)$ \\
\hline Other & $0(0 \%)$ & $2(2 \%)$ \\
\hline \multicolumn{3}{|l|}{ Mother's highest educational level } \\
\hline No qualifications & $1(1 \%)$ & $3(3 \%)$ \\
\hline Mandatory secondary education (eg. GCSEs) & $17(15 \%)$ & $16(14 \%)$ \\
\hline Further education (eg. A levels, BTEC, NVQ) & $32(29 \%)$ & $33(29 \%)$ \\
\hline Higher education (eg. BA, BSc) & $46(41 \%)$ & $46(41 \%)$ \\
\hline Post graduate education (eg, MA, MSc, PhD) & $16(14 \%)$ & $14(13 \%)$ \\
\hline \multicolumn{3}{|l|}{ Father's highest educational level } \\
\hline No qualifications & $5(4 \%)$ & $2(2 \%)$ \\
\hline Mandatory secondary education (eg, GCSEs) & $29(26 \%)$ & $29(26 \%)$ \\
\hline Further education (eg, A levels, BTEC, NVQ) & $33(29 \%)$ & $35(31 \%)$ \\
\hline Higher education (eg, BA, BSc) & $34(30 \%)$ & $32(29 \%)$ \\
\hline Post graduate education (eg, MA, MSc, PhD) & $11(9 \%)$ & $14(13 \%)$ \\
\hline
\end{tabular}




\begin{tabular}{|c|c|c|}
\hline & $\begin{array}{c}\begin{array}{c}\text { Psychoeducation } \\
\text { (control) } \\
(\mathbf{N}=112) \\
\text { N }(\%)\end{array}\end{array}$ & $\begin{array}{c}\text { ERP } \\
\text { (intervention) } \\
(\mathbf{N}=112) \\
\mathrm{N}(\%)\end{array}$ \\
\hline \multicolumn{3}{|l|}{ Mother's occupational status } \\
\hline Not in work / unemployed & $22(20 \%)$ & $19(20 \%)$ \\
\hline Lower occupational status $\$$ & $26(23 \%)$ & $24(21 \%)$ \\
\hline Higher occupational status $\$ \$$ & $57(51 \%)$ & $65(58 \%)$ \\
\hline Other & $7(6 \%)$ & $4(4 \%)$ \\
\hline \multicolumn{3}{|l|}{ Father's occupational status } \\
\hline Not in work / unemployed & $4(4 \%)$ & $2(2 \%)$ \\
\hline Lower occupational status & $30(27 \%)$ & $33(29 \%)$ \\
\hline Higher occupational status & $67(60 \%)$ & $65(58 \%)$ \\
\hline Other & $10(9 \%)$ & $12(11 \%)$ \\
\hline \multicolumn{3}{|l|}{ Tic typology } \\
\hline Both motor and vocal tics & $106(95 \%)$ & $103(92 \%)$ \\
\hline Motor tics only & $6(5 \%)$ & $9(8 \%)$ \\
\hline Vocal tics only & $0(0 \%)$ & $0(0 \%)$ \\
\hline \multicolumn{3}{|l|}{ Comorbidities } \\
\hline Anxiety disorder & $27(24 \%)$ & $34(30 \%)$ \\
\hline Attention deficit hyperactivity disorder (ADHD) & $25(22 \%)$ & $26(23 \%)$ \\
\hline Oppositional defiant disorder (ODD) & $23(21 \%)$ & $26(24 \%)$ \\
\hline Autism spectrum disorders & $4(4 \%)$ & $9(8 \%)$ \\
\hline Obsessive compulsive disorder (OCD) & $3(3 \%)$ & $8(7 \%)$ \\
\hline Major depression & $6(5 \%)$ & $2(2 \%)$ \\
\hline Conduct disorder & $2(2 \%)$ & $3(3 \%)$ \\
\hline Bipolar disorder & .. & .. \\
\hline Taking any tic medication* & $16(13 \%)$ & $14(13 \%)$ \\
\hline \multicolumn{3}{|l|}{ Centre } \\
\hline Nottingham & $57(51 \%)$ & $57(51 \%)$ \\
\hline London & $55(49 \%)$ & $55(49 \%)$ \\
\hline
\end{tabular}

Notes: Statistics are $n(\%)$ unless otherwise specified. $S D=$ standard deviation. Percentages are given to the nearest whole number. Comorbidities are based on $>=50 \%$ probability of having a DSMIV / DSM 5 diagnosis as assessed by the Development and Wellbeing Assessment (DAWBA). Anxiety disorders include separation anxiety, specific phobias, social phobia, panic disorder, agoraphobia and post traumatic stress disorder (PTSD). Diagnoses are not mutually exclusive and so percentages are not expected to total 100\%. Denominators for percentages for comorbidities are not always the full sample, because insufficient information was supplied for some participants to make either a positive or negative diagnosis. Insufficient information was supplied to assess bipolar disorder for all participants. *Any tic medication included: Clonidine, Risperidone, Aripiprazole, Haloperidol, Guanfacine, Topiramate. ${ }^{\$}$ Lower occupational statuses are defined as manual or semi-manual occupations. ${ }^{\$ \$}$ Higher occupational statuses are defined as professional occcupations. ERP = exposure and response prevention. 
Table 2. Primary and secondary outcomes at baseline

\begin{tabular}{|c|c|c|}
\hline & $\begin{array}{c}\text { Psychoeducation } \\
\text { (control) } \\
(\mathbf{N}=\mathbf{1 1 2}) \\
\text { Mean (SD) }\end{array}$ & $\begin{array}{c}\text { ERP } \\
\text { (intervention) } \\
(\mathbf{N}=\mathbf{1 1 2}) \\
\text { Mean }(\mathrm{SD})\end{array}$ \\
\hline \multicolumn{3}{|l|}{ Primary outcome } \\
\hline $\begin{array}{l}\text { Total Tic Severity Score (TTSS) on the } \\
\text { Yale Global Tic Severity Scale (YGTSS) }\end{array}$ & $28 \cdot 4(7 \cdot 1)$ & $28 \cdot 4(7 \cdot 7)$ \\
\hline \multicolumn{3}{|l|}{ Secondary outcomes } \\
\hline $\begin{array}{l}\text { Impairment score on the } \\
\text { Yale Global Tic Severity Scale (YGTSS) }\end{array}$ & $22 \cdot 9(9 \cdot 9)$ & $23 \cdot 8(10 \cdot 3)$ \\
\hline Parent Tic Questionnaire (PTQ) & $53 \cdot 1(26 \cdot 1)$ & $54 \cdot 7(29 \cdot 9)$ \\
\hline Children's Global Assessment Scale (CGAS) & $72 \cdot 1(11 \cdot 8)$ & $70 \cdot 7(13 \cdot 7)$ \\
\hline Strengths and Difficulties Questionnaire (SDQ) & $16 \cdot 3(6 \cdot 2)$ & $18 \cdot 0(6 \cdot 5)$ \\
\hline Mood and Feelings Questionnaire (MFQ) & $15 \cdot 9(11 \cdot 5)$ & $16 \cdot 3(11 \cdot 3)$ \\
\hline Spence Child Anxiety Scale (SCAS) & $30 \cdot 5(17 \cdot 9)$ & $32 \cdot 9(20 \cdot 2)$ \\
\hline $\begin{array}{l}\text { Child and Adolescent Gilles de la Tourette } \\
\text { Syndrome-Quality of Life Scale (C\&A-GTS- } \\
\text { QOL) }\end{array}$ & $35 \cdot 0(17 \cdot 2)$ & $36 \cdot 6(16 \cdot 4)$ \\
\hline
\end{tabular}

Notes: Statistics are mean (SD) unless otherwise specified and are calculated for all available data. $S D=$ standard deviation. Higher scores on the C\&A-GTS-QOL indicate worse quality of life. There was 1 missing value for the SCAS scale. All other measures were complete. ERP = exposure and response prevention. 
Table 3. Effect of the behavioural therapy intervention on primary and secondary outcomes at 3 and 6 months follow up

\begin{tabular}{|c|c|c|c|c|c|c|}
\hline & \multicolumn{3}{|c|}{3 months follow up (primary endpoint) } & \multicolumn{3}{|c|}{6 months follow up } \\
\hline & \begin{tabular}{|c|} 
Psychoeducation \\
(control) \\
$(\mathbf{N}=\mathbf{1 1 2})$ \\
Mean (SD)
\end{tabular} & $\begin{array}{c}\text { ERP } \\
\text { (intervention) } \\
(\mathbf{N}=\mathbf{1 1 2}) \\
\text { Mean (SD) }\end{array}$ & $\begin{array}{l}\text { Estimated } \\
\text { difference } \\
(95 \% \text { CI })\end{array}$ & \begin{tabular}{|} 
Psychoeducation \\
(control) \\
$(\mathbf{N}=\mathbf{1 1 2})$ \\
Mean (SD)
\end{tabular} & $\begin{array}{c}\text { ERP } \\
\text { (intervention) } \\
(\mathbf{N}=\mathbf{1 1 2}) \\
\text { Mean (SD) }\end{array}$ & $\begin{array}{r}\text { Estimated } \\
\text { difference } \\
(95 \% \mathrm{CI})\end{array}$ \\
\hline \multicolumn{7}{|c|}{ Primary outcome } \\
\hline $\begin{array}{l}\text { Total Tic } \\
\text { Severity } \\
\text { Score (TTSS) } \\
\text { on the Yale } \\
\text { Global Tic } \\
\text { Severity } \\
\text { Scale } \\
\text { (YGTSS) }\end{array}$ & $26 \cdot 8(7 \cdot 3)$ & $23 \cdot 9(8 \cdot 2)$ & $\begin{array}{c}-2 \cdot 29 * \\
(-3 \cdot 86 \text { to } \\
-0.71)\end{array}$ & $25 \cdot 0(7 \cdot 6)$ & $21 \cdot 5(8 \cdot 8)$ & $\begin{array}{c}-2 \cdot 64^{*} \\
(-4.56 \text { to }- \\
0.73)\end{array}$ \\
\hline $\begin{array}{l}\text { Standardised } \\
\text { effect size }\end{array}$ & .. & .. & $\begin{array}{c}-0.31 * \\
(-0.52 \text { to } \\
-0.10)\end{array}$ & .. & .. & $\begin{array}{c}-0.36^{*} \\
(-0.62 \text { to }- \\
0 \cdot 10)\end{array}$ \\
\hline \multicolumn{7}{|c|}{ Secondary outcomes } \\
\hline $\begin{array}{l}\text { Total Motor } \\
\text { Tic Score on } \\
\text { the Yale } \\
\text { Global Tic } \\
\text { Severity } \\
\text { Scale } \\
\text { (YGTSS) }\end{array}$ & $15 \cdot 1(3 \cdot 3)$ & $13 \cdot 6(4 \cdot 0)$ & $\begin{array}{c}-1.28 * \\
(-2.07 \text { to } \\
-0.49)\end{array}$ & $14 \cdot 1(3 \cdot 7)$ & $12 \cdot 7(4 \cdot 3)$ & $\begin{array}{c}-1 \cdot 19 * \\
(-2 \cdot 20 \text { to }- \\
0 \cdot 17)\end{array}$ \\
\hline $\begin{array}{l}\text { Total Phonic } \\
\text { Tic Score on } \\
\text { the Yale } \\
\text { Global Tic } \\
\text { Severity } \\
\text { Scale } \\
\text { (YGTSS) }\end{array}$ & $11 \cdot 7(5 \cdot 0)$ & $10 \cdot 2(5 \cdot 3)$ & $\begin{array}{c}-1 \cdot 05 \\
(-2 \cdot 13 \text { to } \\
0.02)\end{array}$ & $10 \cdot 9(5 \cdot 3)$ & $8 \cdot 8(5 \cdot 7)$ & $\begin{array}{c}-1 \cdot 56^{*} \\
(-2 \cdot 8 \text { to }- \\
0 \cdot 29)\end{array}$ \\
\hline $\begin{array}{l}\text { Impairment } \\
\text { score on the } \\
\text { Yale Global } \\
\text { Tic Severity } \\
\text { Scale } \\
\text { (YGTSS) }\end{array}$ & $19 \cdot 1(10 \cdot 9)$ & $16 \cdot 7(10 \cdot 4)$ & $\begin{array}{c}-2 \cdot 24 \\
(-4 \cdot 82 \text { to } \\
0 \cdot 33)\end{array}$ & $17 \cdot 0(10 \cdot 5)$ & $14 \cdot 7(10 \cdot 7)$ & $\begin{array}{c}-1.95 \\
(-4.68 \text { to } \\
0.78)\end{array}$ \\
\hline $\begin{array}{l}\text { Parent Tic } \\
\text { Questionnaire } \\
\text { (PTQ) }\end{array}$ & $45 \cdot 7(25 \cdot 5)$ & $34 \cdot 7(26 \cdot 4)$ & $\begin{array}{c}-9 \cdot 44^{*} \\
(-15 \cdot 37 \\
\text { to }-3 \cdot 51) \\
\end{array}$ & $40 \cdot 6(24 \cdot 3)$ & $31 \cdot 1(21 \cdot 6)$ & $\begin{array}{c}-8 \cdot 60 * \\
(-14.43 \text { to }- \\
2 \cdot 77) \\
\end{array}$ \\
\hline $\begin{array}{l}\text { Clinical } \\
\text { Global } \\
\text { Impression } \\
\text { Scale - } \\
\text { Improvement } \\
\text { (CGI-I) }\end{array}$ & $3 \cdot 37(1 \cdot 11)$ & $2 \cdot 96(1 \cdot 1)$ & $\begin{array}{c}-0 \cdot 41 * \\
(-0.71 \text { to } \\
-0 \cdot 11)\end{array}$ & $3 \cdot 1(1 \cdot 1)$ & $2 \cdot 8(1 \cdot 3)$ & $\begin{array}{c}-0.31 \\
(-0.66 \text { to } \\
0.03)\end{array}$ \\
\hline
\end{tabular}




\begin{tabular}{|c|c|c|c|c|c|c|}
\hline & \multicolumn{3}{|c|}{3 months follow up (primary endpoint) } & \multicolumn{3}{|c|}{6 months follow up } \\
\hline & \begin{tabular}{|c|}
$\begin{array}{c}\text { Psychoeducation } \\
\text { (control) }\end{array}$ \\
$(\mathbf{N}=\mathbf{1 1 2})$ \\
Mean (SD)
\end{tabular} & $\begin{array}{c}\text { ERP } \\
\text { (intervention) } \\
(\mathbf{N}=\mathbf{1 1 2}) \\
\text { Mean (SD) }\end{array}$ & $\begin{array}{l}\text { Estimated } \\
\text { difference } \\
(95 \% \text { CI })\end{array}$ & \begin{tabular}{|} 
Psychoeducation \\
(control) \\
$(\mathbf{N}=\mathbf{1 1 2})$ \\
Mean (SD)
\end{tabular} & $\begin{array}{c}\text { ERP } \\
\text { (intervention) } \\
(\mathbf{N}=\mathbf{1 1 2}) \\
\text { Mean (SD) }\end{array}$ & $\begin{array}{r}\text { Estimated } \\
\text { difference } \\
(95 \% \mathrm{CI})\end{array}$ \\
\hline $\begin{array}{l}\text { Children's } \\
\text { Global } \\
\text { Assessment } \\
\text { Scale } \\
\text { (CGAS) }\end{array}$ & $75 \cdot 2(12 \cdot 6)$ & $75 \cdot 9(12 \cdot 6)$ & $\begin{array}{c}0.96 \\
(-1.48 \text { to } \\
3.41)\end{array}$ & $76 \cdot 8(12 \cdot 3)$ & $77 \cdot 5(14 \cdot 7)$ & $\begin{array}{c}0 \cdot 60 \\
(-2 \cdot 24 \text { to } \\
3 \cdot 44)\end{array}$ \\
\hline $\begin{array}{l}\text { Strengths and } \\
\text { Difficulties } \\
\text { Questionnaire } \\
\text { (SDQ) }\end{array}$ & $14.2(6.3)$ & $14.7(6.1)$ & $\begin{array}{l}-0.38 \\
(-1.62 \\
\text { to } 0.85)\end{array}$ & $13 \cdot 3(6 \cdot 1)$ & $15 \cdot 3(6 \cdot 2)$ & $\begin{array}{c}0.57 \\
(-0.93 \text { to } \\
2.07)\end{array}$ \\
\hline $\begin{array}{l}\text { Mood and } \\
\text { Feelings } \\
\text { Questionnaire } \\
\text { (MFQ) }\end{array}$ & $12.6(11.1)$ & $10.7(11.1)$ & $\begin{array}{c}-1 \cdot 36 \\
(-3 \cdot 75 \text { to } \\
1 \cdot 02)\end{array}$ & $11 \cdot 4(11 \cdot 2)$ & $11 \cdot 4(12 \cdot 1)$ & $\begin{array}{c}-0.61 \\
(-3.85 \text { to } \\
2.64)\end{array}$ \\
\hline $\begin{array}{l}\text { Spence Child } \\
\text { Anxiety } \\
\text { Scale (SCAS) }\end{array}$ & $28.2(18.3)$ & $27.2(19.0)$ & $\begin{array}{c}-2 \cdot 80 \\
(-6.52 \text { to } \\
0.93)\end{array}$ & $25 \cdot 9(18 \cdot 7)$ & $25 \cdot 7(19 \cdot 6)$ & $\begin{array}{c}-5 \cdot 10^{*} \\
(-9 \cdot 70 \text { to }- \\
0 \cdot 50)\end{array}$ \\
\hline $\begin{array}{l}\text { Child and } \\
\text { Adolescent } \\
\text { Gilles de la } \\
\text { Tourette } \\
\text { Syndrome-- } \\
\text { Quality of } \\
\text { Life Scale } \\
\text { (C\&A-GTS- } \\
\text { QOL) }\end{array}$ & $31.8(17.7)$ & $25.7(18.0)$ & $\begin{array}{c}-4 \cdot 81 \\
(-8 \cdot 79 \text { to } \\
-0 \cdot 83)\end{array}$ & $28 \cdot 9(18 \cdot 3)$ & $27 \cdot 4(16 \cdot 5)$ & $\begin{array}{c}-2.91 \\
(-7 \cdot 60 \text { to } \\
1.78)\end{array}$ \\
\hline
\end{tabular}

Notes: Statistics are mean (SD) unless otherwise specified. $S D=$ standard deviation. $C I=$ confidence interval. *Indicates statistically significant result. Statistical models adjusted for the baseline measure of the outcome in question (with the exception of the CGI-I) and site. For the standardised effect size, YGTSS-TTSS was standardised by the pooled mean and SD at baseline. Higher scores on the $C \& A$ GTS-QOL indicate worse quality of life. At 3 months follow up, there were 12 missing observations (11\%) for the primary outcome in the ERP arm compared to 11 (10\%) in the psychoeducation arm. The quantity of missing data for secondary outcomes was similar in both trial arms. ERP = exposure and response prevention. 
Table 4. Response to treatment at 3 and 6 months follow-up

\begin{tabular}{|c|c|c|c|c|c|c|}
\hline & \multicolumn{3}{|c|}{3 months follow up } & \multicolumn{3}{|c|}{6 months follow up } \\
\hline & $\begin{array}{c}\text { Psychoeducation } \\
\text { (control) } \\
(\mathbf{N}=\mathbf{1 0 0}) \\
\mathrm{N}(\%)\end{array}$ & $\begin{array}{c}\text { ERP } \\
\text { (intervention) } \\
(\mathbf{N}=\mathbf{1 0 1}) \\
\mathrm{N}(\%)\end{array}$ & $\begin{array}{c}\text { Odds } \\
\text { ratio } \\
(95 \% \\
\text { CI })\end{array}$ & $\begin{array}{c}\text { Psychoeducation } \\
\text { (control) } \\
(\mathbf{N}=93) \\
\mathrm{N}(\%)\end{array}$ & $\begin{array}{c}\text { ERP } \\
\text { (intervention) } \\
(\mathbf{N}=93) \\
\mathrm{N}(\%)\end{array}$ & $\begin{array}{c}\text { Odds } \\
\text { ratio } \\
(95 \% \\
\text { CI) }\end{array}$ \\
\hline $\begin{array}{l}\text { CGI-I scored } \\
\text { indicating } \\
\text { 'much' or } \\
\text { 'very much' } \\
\text { improved } \\
\text { (responded to } \\
\text { treatment) }\end{array}$ & $20(20 \%)$ & $36(36 \%)$ & $\begin{array}{l}2.22 * \\
(1 \cdot 17 \\
\text { to } \\
4 \cdot 20)\end{array}$ & $27(29 \%)$ & $44(47 \%)$ & $\begin{array}{l}2.20^{*} \\
(1.20 \\
\text { to } \\
4.04)\end{array}$ \\
\hline \multicolumn{7}{|c|}{ Change in response between 3 and 6 months } \\
\hline $\begin{array}{l}\text { No response to } \\
\text { treatment at } \\
\text { either time }\end{array}$ &.. & .. & .. & 56 / $93(60 \%)$ & $\begin{array}{l}37 / 90 \\
(41 \%)\end{array}$ & .. \\
\hline $\begin{array}{l}\text { Response at } \\
\text { both time }\end{array}$ & .. & .. & .. & $9 / 93(10 \%)$ & $\begin{array}{l}23 / 90 \\
(26 \%) \\
\end{array}$ & .. \\
\hline $\begin{array}{l}\text { New responder } \\
\text { at } 6 \text { months }\end{array}$ & .. & .. & .. & $18 / 93(19 \%)$ & $\begin{array}{l}20 / 90 \\
(22 \%) \\
\end{array}$ & .. \\
\hline $\begin{array}{l}\text { Relapsed } \\
\text { responder at } 6 \\
\text { months }\end{array}$ & .. & .. & .. & $10 / 93(11 \%)$ & $\begin{array}{l}10 / 90 \\
(11 \%)\end{array}$ &.$\cdot$ \\
\hline
\end{tabular}

Notes: Statistics are frequency (N) and percentage (\%) unless otherwise specified. *Indicates statistically significant. CGI-I = Clinical Global Impressions - Improvement. $C I=$ confidence interval. Statistical models adjusted for site. ERP = exposure and response prevention. 
Table 5. Engagement with the intervention and perception of treatment suitability and credibility

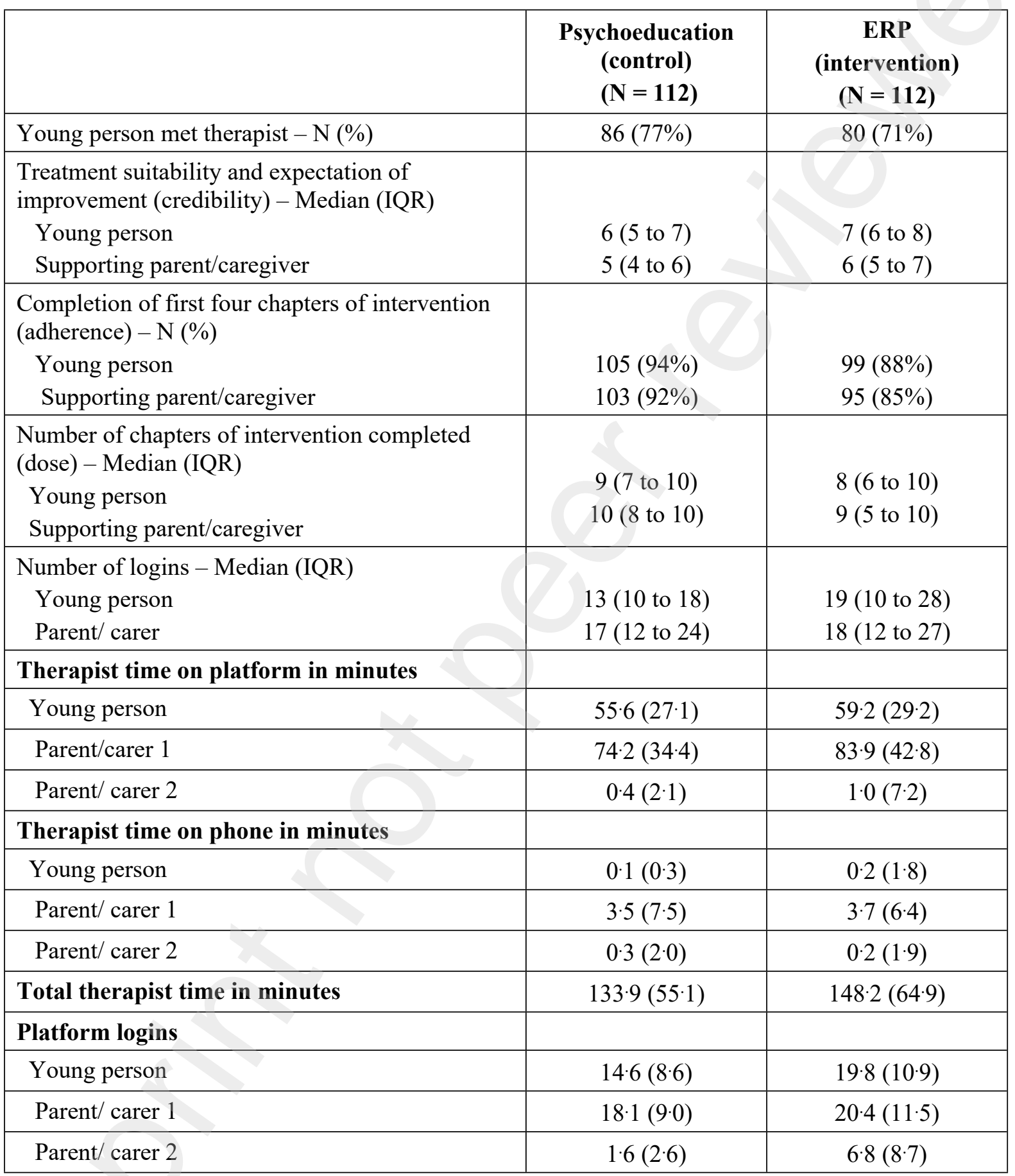

Notes: Statistics are as specified. IQR = interquartile range. Treatment completers defined as young person completion of first four chapters. ERP = exposure and response prevention. 
Table 6. Comparison of variable costs between the psychoeducation (control) and ERP (intervention) group across the 6 months

\begin{tabular}{|c|c|c|c|}
\hline & $\begin{array}{l}\text { Psychoeducation } \\
\text { (control) } \\
(\mathbf{N}=111)\end{array}$ & $\begin{array}{c}\text { ERP } \\
\text { (Intervention) } \\
(\mathrm{N}=\mathbf{1 1 1})\end{array}$ & $\begin{array}{l}\text { Difference at } 6 \text { months } £ \\
(95 \% \mathrm{CI})\end{array}$ \\
\hline & Mean (SD) $£$ & Mean $(\mathrm{SD}) £$ & \\
\hline \multicolumn{4}{|c|}{ Cost of therapist contact time } \\
\hline Young person & $16(9)$ & $18(9)$ & \\
\hline Parent/ carer 1 & $22(10)$ & $25(13)$ & \\
\hline Parent/ carer 2 & $0.09(0.56)$ & $0 \cdot 20(2)$ & \\
\hline Total & $38(17)$ & $43(20)$ & $4.99 *(0.01$ to 9.96$)$ \\
\hline \multicolumn{4}{|l|}{ Login costs } \\
\hline Young person & $3(1)$ & $3(2)$ & \\
\hline Parent/ carer 1 & $3(2)$ & $3(2)$ & \\
\hline Parent/ carer 2 & $0 \cdot 01(0 \cdot 10)$ & $0.04(0.33)$ & \\
\hline Total & $6(3)$ & $7(4)$ & $1.25 *(0.46$ to 2.04$)$ \\
\hline Total variable costs & $44(18)$ & $50(22)$ & $6.27(0.88$ to 11.67$)$ \\
\hline
\end{tabular}

Note: *Indicates statistically significant. $C I=$ confidence interval. ERP $=$ exposure and response prevention. 
Figure 1. Trial recruitment and retention

Note.

$B T=$ behavioural therapy. $C A I D S-Q$ $=$ Child and Adolescent Intellectual Disability Screening Questionnaire. $D A W B A=$ development and wellbeing assessment. $D S H=$ deliberate self-harm. ERP = exposure and response prevention. PIC $=$ participant identification centre. YGTSS = Yale Global Tic Severity Scale. Follow-up rate given as number (\%) completing primary outcome measure. * completed $\geq 4$ chapter

\section{Excluded $(n=210)$}

- Declined to participate $(n=84)$

-No specific reason specified from the family (46)

-Child did not want to participate (18)

-Didn't want to attend baseline appointment (10)

-Tics not current priority (5)

-Family difficulties/ insufficient time (5)

Didn't meet inclusion criteria from screen $(n=60)$

-Had BT in last 12 months or due to start BT (21)

-Lives outside of England (11)

-Immediate risk to self or others (8)

- Tourette's/Chronic tic disorder diagnosis not fulfilled (7)

-Outside age range (5)

-Likely to have moderate/severe intellectual disability (2)

-Child has eating disorder (2)

- Recently started new tic medication (3)

-Another family member is already in the trial (1)

- Family uncontactable $(n=47)$

- DAWBA exclusion ( $n=19$

- Deliberate self harm (DSH) (18)

Attended baseline/screening appointment ( $n=235)$

-Eating disorder concerns and hallucinations (1)

\section{Excluded ( $\mathrm{n}=11$ )}

- Sub-threshold CAIDSQ score (5)

- Had BT in last 12 months. (1)

- Evidence of DSH not score detected by DAWBA (1)

- Sub-threshold YGTSS score (3)

- Didn't understand study purpose (1)

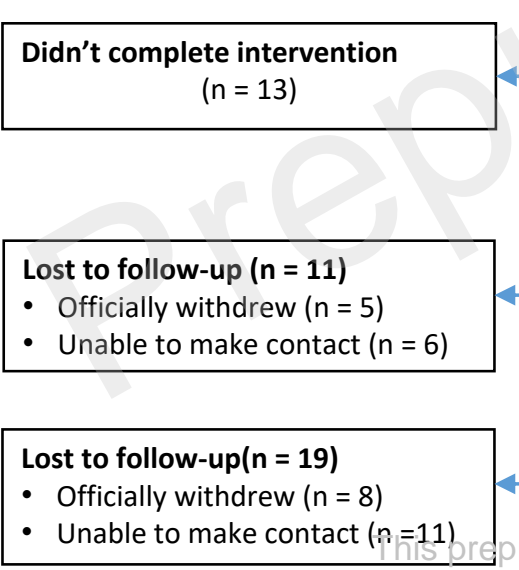

Allocated ERP intervention $(n=112)$

Received min intervention* ( $n=99 / 112)(88 \%)$

Randomised $(n=224) *$

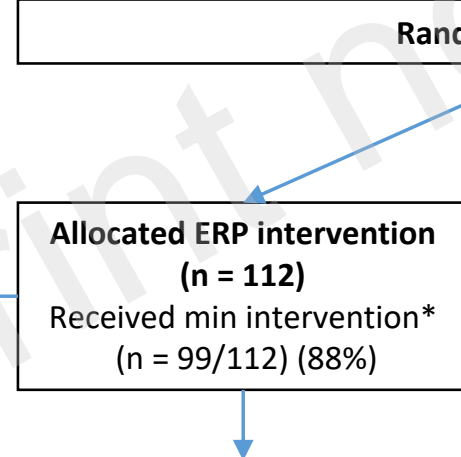

Follow up at 3 mths $(\mathrm{n}=$ $101 / 112(90 \%)$

Follow up at $6 \mathrm{mths}(\mathrm{n}=$ 93/112) (83\%)

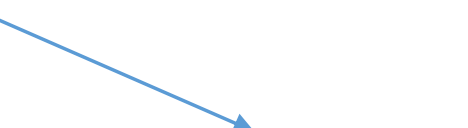

\section{Allocated psychoeducation} control $n=112$

Received min intervention* $(n=105 / 112)(94 \%)$

Didn't complete intervention

$$
(n=7)
$$

Lost to follow-up ( $\mathbf{n}=12)$

Officially withdrew $(n=5)$

- Unable to make contact $(n=7)$

Follow up at 3mths ( $n=100 / 112)(89 \%)$

Follow up at $6 \mathrm{mths}$

Lost to follow-up(n = 19)

Officially withdrew $(n=9)$ 


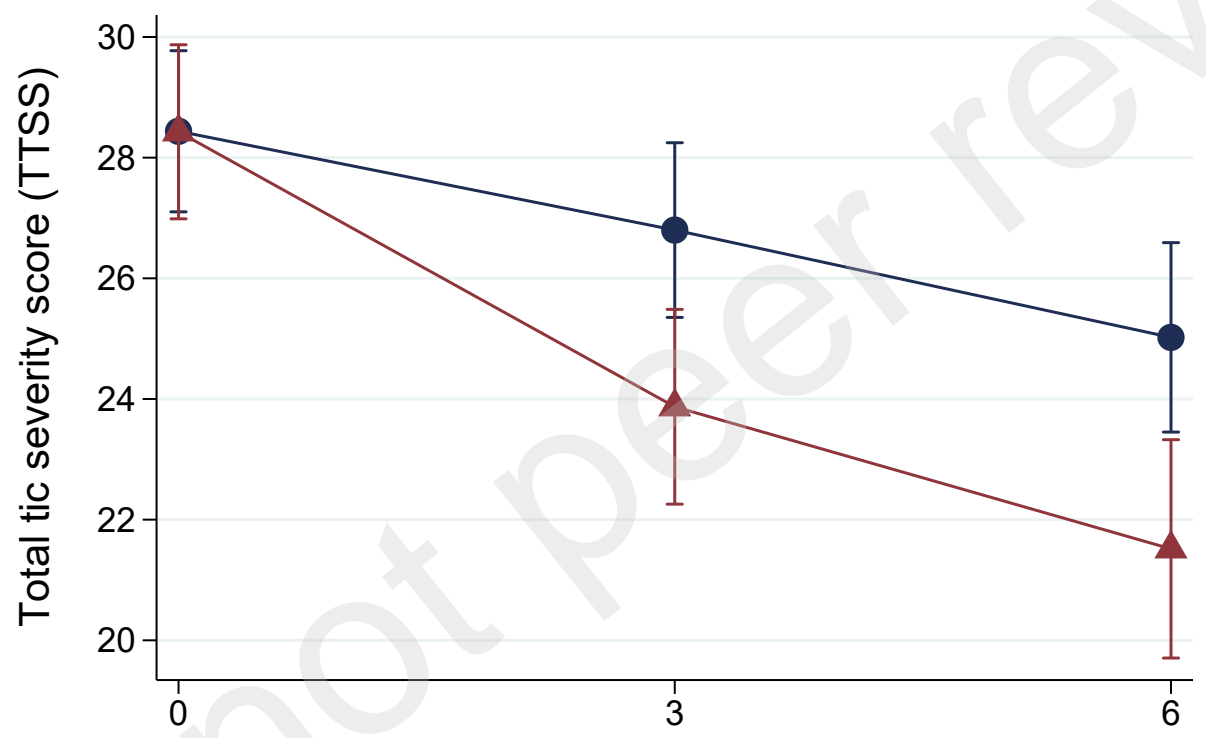

Time (months) 


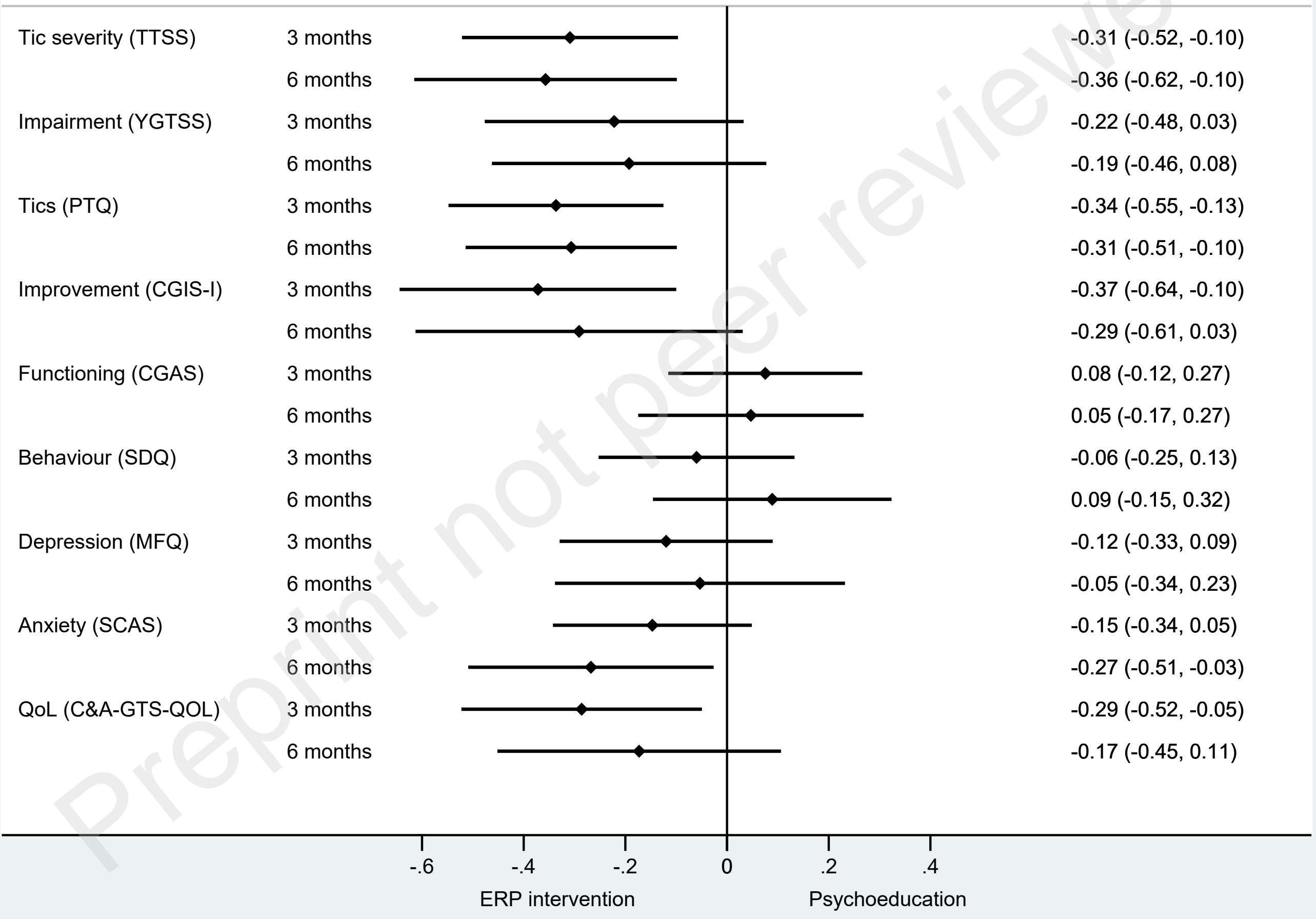

